\title{
Os procedimentos de controle e a resistência na prática jornalística ${ }^{1}$
}

Beatriz Alcaraz Marocco

Resumo: Uma coleção de entrevistas com jornalistas evidenciou um processo de autonomização na prática jornalística. Durante o jogo de perguntas e respostas, para surpreendê-los em suas ilusões sobre si e o jornalismo, construímos um aparelho teórico-metodológico que acionou as noções de consciência discursiva e os procedimentos de controle que afetam a prática (MAROCCO, 212a). Na análise enunciativa dos dados, que deu origem ao presente texto, localizamos no bojo de quatro figuras discursivas a tensão entre procedimentos de controle e resistência na prática jornalística.

Palavras-chave: controles discursivos; prática jornalística; entrevista; consciência discursiva.

Abstract: Control procedures and the resistance in the journalistic practice - A collection of interviews with journalists has put in evidence a process of autonomization in the journalistic practice. During the asking and answering game, in order to catch them in their illusions about themselves and the journalism, we have constructed a theoretical-methodological device that triggered the notions of discursive consciousness and of control procedures that affect the professional practice (MAROCCO, 212a). In the enunciative analysis of data, which gave birth to the present text, we have detected in the core of four discursive figures the tension between control procedures and the resistance in the journalistic practice.

Keywords: discursive controls; journalistic practice; interview; discursive consciousness.

\section{Práticas e controles discursivos}

Práticas discursivas são constituídas por um corpo de regras anônimas e históricas, determinadas no tempo e no espaço. Qualquer ação pode ser considerada como prática discursiva. Essas regras delimitam o dizível: o que é permitido e o que é proibido nas ações dos membros de uma formação discursiva. Em outras palavras, os sujeitos devem

1 Versão ampliada e revista do texto apresentado no XII SBPJor, Santa Cruz do Sul, 2014. 
se comportar de acordo com essas práticas discursivas ou formas de comportamento. Dessa perspectiva, os sujeitos são constituídos discursivamente. Para Foucault, não existe sujeito que não seja constituído pelo discursivo. Sujeitos são cúmplices na sua própria constituição discursiva - subjetivação é um modo do ser humano constituir a si mesmo em sujeito.

Pondo foco nas práticas de uma dada formação discursiva, poder-se-á ter uma ideia sobre o funcionamento dos sujeitos discursivos e sobre a natureza da formação discursiva, no caso, a jornalística. No cotidiano de formulação, constituição, cristalização e reformulação do discurso jornalístico, as práticas jornalísticas podem ser associadas a três formas de controle: procedimentos externos, procedimentos internos e procedimentos que não são totalmente internos ou externos.

Os procedimentos externos foram identificados por Foucault nos três "grandes sistemas de exclusão" que atingem o discurso pelo exterior: a palavra proibida, a segregação da loucura e a vontade de verdade (FOCAULT, 1996, p.19). Segundo Dent (2008), as técnicas externas de gestão giram em torno da capacidade dos jornalistas de negar aos outsiders a oportunidade de serem ouvidos. Em outras palavras, elas se referem à habilidade de segregar as pessoas em função do que elas dizem ser proibido ou em função de sua falta de conhecimento sobre o discurso verdadeiro que domina a formação.

A vontade de verdade apoia-se em um suporte institucional e é reconduzida pelo modo como o saber é valorizado, distribuído, repartido e atribuído, por parentesco, a uma época. Há séculos, o jornalismo buscou o apoio da ciência para ganhar o reconhecimento da sociedade, não mais como um discurso de impressões e opiniões do jornalista sobre o cotidiano, na vizinhança da literatura, mas como um discurso "objetivo", "neutro". Nos limites da informação, a palavra do jornalista não poderia mais ser autorizada a não ser com sua entrada em uma ordem do discurso jornalístico fundamentada pela presença da fonte de informação como testemunho da realidade e por uma "prodigiosa maquinaria destinada a excluir todos aqueles que, ponto por ponto, em nossa história, procuraram contornar essa vontade de verdade" (FOUCAULT, 1996, p. 19-20).

Os procedimentos internos de controle discursivo são exercidos pelo próprio discurso (FOUCAULT, 1996, p. 21); incluem os princípios de classificação, ordem e distribuição e são relacionados ao comentário, ao autor e às disciplinas. Os dois primeiros conjuntos de práticas são relacionados com textos privilegiados por um determinado saber. Comentários, por exemplo, operam sobre os textos primários e fornecem repetição e desvendamento de significados ocultos atribuídos aos textos em operações hermenêuticas que não caracterizam o jornalismo. C. Dent (2008) não identificou o comentário no jornalismo. Em relação à objetividade jornalística, Tuchman (1999) havia dito, antes, que o processamento da notícia não deixa tempo para a análise epistemológica reflexiva. Nesse sentido, os jornalistas necessitam de uma "noção operativa" de objetividade para minimizar os riscos potenciais dos prazos de entrega dos materiais produzidos, dos processos por difamação das reprimendas dos superiores. 
A autoria no jornalismo não pode ser relacionada diretamente à função de autor, à medida que esta interfere na obra e nos textos como uma forma de ordem (FOUCAULT, 1996, p. 26). O autor é pressionado a levar em conta a unidade dos textos assinados por ele. É pressionado a revelar ou ao menos dar indícios de autoria para passar ao texto a sua autoridade. No texto jornalístico, essa autoridade se delineia no estilo autoral, mas é diluída no coletivo da redação, nas marcas discursivas de impessoalidade, ou seja, em uma não-autoria em seus efeitos de objetividade. Da perspectiva de Dent (2008), a autoria pode ainda ser identificada na relação difusa da mídia com o leitor; seria a singularidade da mídia, construída por sua linha editorial, que formalizaria tal função ao interferir nos textos como uma outra forma de ordem.

Diferente dos procedimentos de controle do comentário e do autor, a disciplina regula as proposições mais gerais que não estão ligadas a textos ou autores e pode ser vista, igualmente, como uma regulação interna com vistas a produzir efeitos sobre a recepção. "A disciplina é um princípio de controle da produção do discurso. Ela Ihe fixa os limites pelo jogo de uma identidade que tem a forma de uma reatualização permanente das regras" (Foucault, 1996, p. 36). Ancorada nas variáveis tempo e espaço, que dão consistência de presente social de referência ao acontecimento, a disciplina possibilita que o jornalista tome decisões rápidas relativamente à validade, fiabilidade e "verdade" para levar a cabo o processamento da informação e a edição das notícias.

O último conjunto de controles discursivos pode ser visto como procedimentos nem totalmente externos, nem totalmente internos. São processos de "rarefação" dos sujeitos que falam e que, no caso jornalístico, que constituem uma hierarquia organizacional. Se o saber jornalístico é considerado, nem todos os membros do público têm a capacidade de falar o que é considerado verdade para esta formação, embora alguns possam reivindicar um lugar no jornal como fonte, articulista, comentarista, enquanto outros são altamente mal vistos. Dentro da profissão, nem todas as posições são igualmente abertas e acessíveis até aos profissionais mais experientes. Assim, a hierarquia jornalística pode ser entendida como dispositivo ${ }^{2}$ de controle interno - para crítica, classificação e ordenamento dos materiais -, mas não pode ser tomada como uma forma de controle das pessoas de fora da profissão, que têm ou não acesso às mídias e que formam ou não os seus públicos.

\section{Relação dialógica}

Sobre a entrevista, nos diz Morin que se trata de "uma comunicação pessoal suscitada com uma finalidade de informação" que é praticada tanto em psicologia social, se tem caráter científico, como na imprensa, no rádio, no cinema ou na televisão (MORIN, 2000, p. 207). A diferença reside na natureza da informação.

2 Nas palavras de Deleuze, dispositivo, em uma perspectiva foucaultiana, é o não lugar, em que se precipita o diagrama informal que se encarna em duas formas de atualização (visível e enunciável), diferenciadas, irredutíveis uma a outra (DELEUZE, 1987, p. 65). 
A informação em ciências sociais faz parte de um sistema metodológico, hipotético e verificador. A informação da entrevista científica deve ser, primeiramente, interessante para um pequeno grupo de pesquisadores. A informação da entrevista mass mediática deve ser, primordialmente, interessante para um público vasto (MORIN, 2000, p. 207).

No âmbito da psicologia social, a entrevista foi inicialmente localizada em duas grandes ramificações: extensiva, quando feita pela aplicação de questionários em grandes mostras da população, gerando uma formulação estatística de resultados, e intensiva, quando trata de aprofundar o conteúdo da comunicação. Nesse sentido, os dois tipos extremos de entrevista podem opor-se. Em outro sentido, podem combinar-se.

Conversações profundas preparam a elaboração de questionários que serão utilizados segundo o método das sondagens de opinião; e inversamente as sondagens mediante questionários podem permitir a seleção dos sujeitos que serão submetidos a entrevistas profundas (MORIN, 2000, p. 2009).

No nível da prática jornalística, a entrevista é definida por Cremilda Medina como um diálogo que pode tanto acentuar a incomunicação como estar diretamente relacionado com a humanização do contato interativo.

Sua maior ou menor comunicação está diretamente relacionada com a humanização do contato interativo: quando, em um desses raros momentos, ambos - entrevistado e entrevistador - saem "alterados" do encontro, a técnica foi ultrapassada pela "intimidade" [...]. Tanto um como outro se modificaram, alguma coisa aconteceu que os perturbou [...]. Ou seja, realizou-se o Diálogo Possível (MEDINA, 1990, p. 7).

Esquadrinhar a prática dando a palavra aos jornalistas, em longas entrevistas, este foi o caminho escolhido durante a pesquisa para ouvi-los sobre as suas práticas. Dois tipos de consciência da prática social abrangem tanto os motivos inconscientes como a monitoração reflexiva desta conduta: a consciência prática, em que os indivíduos conhecem as condições de possibilidade da sua própria ação, mas não se expressam sobre elas; e a consciência discursiva, em que são capazes de expressar verbalmente as condições de sua própria ação. A divisão entre as duas, segundo Giddens, pode ser alterada em função de numerosos aspectos da socialização e das experiências acumuladas de aprendizagem. Indivíduos estrategicamente colocados em muitos contextos da vida social também podem regular as condições globais de reprodução do sistema, seja para manter as coisas como estão, seja para mudá-las (GIDDENS, 2009, p. 33).

Todo ator social competente, acrescente-se, é ipso facto um teórico social no nível da consciência discursiva e um "especialista metodológico" nos níveis de consciência prática e discursiva (2009, p. 21). 
Segundo Giddens, à semelhança de alguns itens auto-reprodutores na natureza, as práticas humanas são recursivas. Não são criadas por agentes sociais, mas são recriadas por eles continuamente. O monitoramento reflexivo das atividades é outra característica dessa ação cotidiana, em que os atores controlam e regulam continuamente o fluxo de suas atividades, esperam que os outros façam o mesmo, e mantêm um contínuo entendimento das bases de sua atividade. Nesse monitoramento rotineiro das práticas, os agentes mobilizam a bagagem de conhecimento mútuo que adquiriram e compartilham (GIDDENS, 2009, p. 5).

A ferramenta central, mais próxima das práticas (em seu desdobramento de gênero jornalístico) e mais apropriada para operar nos níveis epistemológico, metodológico e de tratamento de dados, é a entrevista. Em sua potência de dispositivo de revelação da consciência discursiva dos jornalistas, a entrevista engendra um espaço autônomo, em que se desenha, de entrada, um entendimento teórico das bases de sua própria atividade (Giddens, 2009), e em que não existe mais representação em forma de teoria, o intelectual que dizia a verdade àqueles que ainda não a viam e em nome daqueles que não podiam dizê-la, mas "ação de teoria" (DELEUZE, 1993).

Ora, o que os intelectuais descobriram recentemente é que as massas não necessitam deles para saber; elas sabem perfeitamente, claramente, muito melhor do que eles; e elas o dizem muito bem (FOUCAULT, 1993, p. 71).

Essa potência da entrevista colocou-a na centralidade da pesquisa em que foram realizadas 17 entrevistas, de outubro de 2010 a dezembro de 2011 (MAROCCO, 2012). A saliência no mercado, a memória do pesquisador, o reconhecimento dos repórteres que responderam a um questionário enviado por e-mail ${ }^{3}$ e os nomes de colegas mencionados durante as próprias entrevistas foram critérios para seleção dos entrevistados.

\section{Autonomização do jornalista}

O jornalista foi agente e sujeito, nas últimas décadas, de procedimentos diferenciados de aprendizagem, controle da prática e táticas de resistência. De aprendiz solitário e solidário com os colegas, nos anos 60, o "foca" foi sendo gradualmente assujeitado a um processo ininterrupto de transmissão de conhecimento sobre a prática. A experiência de aprendiz em funções subalternas corresponderá, na continuidade, à posição de peça da engrenagem que faz circular o saber jornalístico que aprendeu e fará circular entre os novos iniciantes. Nessa posição, o jornalista pode ser associado a procedimentos de controle

3 Um questionário de 49 perguntas foi enviado por e-mail a 269 repórteres do interior do Rio Grande do Sul e a 477 dos jornais Zero Hora, Folha de S. Paulo e O Estado de S. Paulo, entre 18 de maio e 17 de agosto de 2010. Entre os primeiros, que participaram da primeira fase da pesquisa, obtivemos uma taxa de resposta de $21,18 \%$ (57 respostas para 269 e-mails). A taxa de resposta do segundo grupo, durante a outra fase da pesquisa, foi de $15,30 \%$ (73 respostas para 477 e-mails). No total da pesquisa, a taxa de resposta atingiu 17,42\% (130 respostas para 746 e-mails). 
interno, que estão ligados à disciplina e ao regime de verdade que torna o jornalismo aquilo que ele é e não outra coisa, história ou literatura, por exemplo, e a quatro figuras discursivas esboçadas durante as entrevistas da pesquisa e que foram definidas nas relações enunciativas formuladas nas operações de análise.

1. Figura que ensina a prática jornalística e faz funcionar o discurso da formação, seu regime de verdade.

2. Figura que atua como ponto de reprodução das "táticas" próprias que não reconhecem ou que neutralizam os controles da redação.

3. Figura que resiste à segregação do outro.

4. O autor

No conjunto de entrevistas, a rede formada por Núbia Silveira ${ }^{4}$, Celito De Grandi ${ }^{5}$, Ricardo Stefanelli ${ }^{6}$ e Marta Gleich ${ }^{7}$ evidenciou a existência destas diferentes posições, de aprendiz e mestre na memória de interagentes bem identificados na esfera da prática. Núbia Silveira, nossa primeira entrevistada, era repórter quando Celito De Grandi ocupava a secretaria de redação do Diário de Notícias de Porto Alegre. Marta Gleich (repórter) aprendeu com Núbia (chefe de redação) na redação de Zero Hora, ensinou outra geração de repórteres e atualmente ocupa a função de diretora de redação do mesmo jornal. Ricardo Stefanelli, que antecedeu Gleich na direção de Zero Hora, entre todos os entrevistados questionou a existência desta engrenagem. Para ele, na Redação, ninguém ensina ninguém; o aprendizado depende da habilidade do foca de esquadrinhar os editores, acompanhar o que o editor faz em relação ao texto dele. Dá certo em uma redação, segundo Stefanelli, quem consegue captar os "macetes". Carlos Eduardo Lins da Silva ${ }^{8}$ tende a pensar que repórter nasce pronto, mas não despreza o que se aprende por si e com os outros.

Na verdade, por mais que tenha editores preparados para dar retorno, dar feedback e acompanhamento, no dia a dia de uma redação, ninguém ajuda ninguém, é preciso ser autodidata (STEFANELLI, 2012, p. 58).

[...] tendo a achar que se aprende mais sozinho. E acho mais ainda: acho que se nasce pronto. Sabe por que? Porque nesses anos, desde 1976, raramente errei ao ver pela primeira vez o texto de alguém e dizer que aquele cara ia ser ou não jornalista. Pegava o texto do cara e dizia: esse cara não vai ser nunca; esse cara vai ser muito bom (LINS DA SILVA, 2012, p. 131-132).

4 Núbia Silveira, na época da entrevista, era diretora de redação do jornal eletrônico Sul 21. É coautora dos livros Ninguém acreditava e Cyro Martins, 100 anos - o homem e seus paradoxos. Trabalhou nos jornais Diário de Notícias, Folha da Manhã, Correio da Manhã, Zero Hora, Jornal do Comércio, O Sul e Diário Catarinense.

5 Celito de Grandi, colunista de Zero Hora, é autor dos livros Loureiro da Silva, o Charrua; Diário de Notícias, o romance de um jornal; Caso Kliemann, a história de uma tragédia.

6 Ricardo Stefanelli, na época da entrevista, era diretor de redação de Zero Hora.

7 Marta Gleich, na época da entrevista, era diretora de internet do grupo RBS.

8 Carlos Eduardo Lins da Silva é professor na ESPM-SP, foi repórter, correspondente internacional e editor de opinião nos Diários Associados, bem como secretário de redação e ombudsman na Folha de S. Paulo. 
Carlos Eduardo Lins e Silva, Laurentino Gomes ${ }^{9}$ e Luiz Cláudio Cunha ${ }^{10}$ derivaram para as alianças com um sem-fim de colegas de diferentes redações do país, que compartilharam suas experiências de ensino/aprendizado arcanas.

Este não é geralmente um ensino estruturado: "Senta aqui que agora eu vou te ensinar como ser jornalista". É agir em cima de situações específicas do dia a dia. Então, às vezes, é uma matéria absolutamente torta da rua. Matéria quadrada. Aí cabe ao editor paciente, experiente, mais generoso com seu repórter, chamar: "Fulano, senta aqui, vamos ver" (LAURENTINO GOMES, 2012, p. 114).

Helle (Alves) [...]. Ela era muito famosa, junto com o repórter fotográfico Antônio Moura foram os primeiros jornalistas a ver o corpo de Che Guevara e fotografá-lo, na Bolívia. Helle era chefe de reportagem. [...] Ela pegava as matérias e lia comigo, mostrava: olha, podia ter sido assim, aqui seria melhor desse jeito. Mas não muito. Quem me ensinou mesmo e eu não mencionei aqui foi um redator, cujo nome nem me lembro, no jornal A Tribuna de Santos [...]. [...] acabei escrevendo algumas matérias para o jornal, ainda adolescente, com 15. E uma delas, que achava o máximo, esse redator copidescou e me chamou para conversar. E quando vi o meu texto, nem li, eu só vi aquele monte de canetada. Foi muito duro comigo, muito útil (LINS DA SILVA, p. 124-125).

Morava em Porto Alegre [...] e pegava dois ônibus até chegar à redação do jornal, na avenida Ipiranga. [...]. Comprava a revista da semana na segunda-feira ainda fresquinha, na banca do Mercado Público, e mal via o tempo passar no ônibus apinhado, às vezes lendo em pé, absorvido, deliciado. Minha atenção estava toda concentrada nos relatos precisos, empolgantes que Paulo Totti, enviado especial a Montevidéu, fazia da convulsão política no Uruguai [...]. Eu queria ser, quando crescesse, um jornalista com o talento de Paulo Totti (CUNHA, 2012, p. 96).

A segunda figura emerge nas bordas ou longe da redação. Eliane Brum ${ }^{11}$ desenvolveu táticas de resistência, aproximando-se de um repórter veterano, até conseguir a sua autonomia com um modo próprio de apurar "desacontecimentos" e o desenvolvimento de uma escritura que se constitui com pessoas ditas comuns, que nunca seriam notícia. Para a repórter, o que é notícia não é um dado da natureza disciplinar do jornalismo, como muita gente parece acreditar. A definição do que é notícia é uma escolha histórica, é uma escolha cultural, é uma escolha política e é uma escolha econômica (BRUM, 2012, p. 86).

9 Laurentino Gomes é autor dos livros 1808 e 1822. Foi repórter e editor de veículos como o jornal O Estado de S. Paulo e a revista Veja.

10 Luiz Cláudio Cunha é autor de Operação Condor - O sequestro dos uruguaios: uma reportagem dos tempos da ditadura e de Assim morreu Tancredo. Foi chefe de redação, em Brasília, das revistas Veja, IstoÉ e Afinal, além dos jornais O Estado de S. Paulo, Jornal do Brasil, Zero Hora e Diário da Indústria e Comércio.

11 Eliane Brum é repórter especial e colunista na revista Época. É autora do romance Uma duas e dos livros de reportagem Coluna Prestes - o avesso da lenda, de $A$ vida que ninguém vê e $O$ olho da rua. 
[...]uma redação é um embate [...] de visões do mundo. São relações de poder e não apenas imposições. [...] O caminho mais difícil é aquele em que vais brigar, vais ficar na geladeira, às vezes até vais ser demitido, em outras, vais ser obrigado a pedir demissão. E muita gente não quer o caminho mais difícil, quer o caminho mais fácil, então culpa o outro (BRUM, 2012, p. 85-86).

Alexandra Lucas Coelho ${ }^{12}$ sentia no início uma vontade caótica de fazer muita coisa e a sua primeira cobertura internacional permitiu-lhe perceber por si o como se faz. Além disso, contou com o acaso. Ela estava passando férias na União Soviética quando se viu no meio do golpe que derrubou Gorbatchev. Às vezes, disse, "é a total inconsciência das nossas limitações que nos leva para frente" (COELHO, 2012, p. 162). Estava com 22 anos.

Somente quando estamos conscientes das nossas limitações é que paralisamos. Então, às vezes, a inconsciência pode ser útil. Ou a vontade, determinação, pode ser muito útil, mesmo que erremos. Só para explicar que, quando aquilo me aconteceu, comecei a fazer várias coisas ao mesmo tempo, para os jornais e para a rádio, numa situação em que eu não tinha a menor ideia de como se fazia. E era uma época em que não havia celulares, não havia internet, não havia computadores [...] (COELHO, 2012, p. 162).

A distância da redação repercute de diferentes modos no aprendizado do correspondente internacional. Fora do ambiente de circulação do saber jornalístico, Carlos Eduardo Lins da Silva passou por um processo totalmente solitário, que excluiu até mesmo as salas de aula do mestrado em Comunicação na Universidade de Michigan. Ele morava no campus e dividia o quarto com um brasileiro, estudante de filosofia, com quem não conversava sobre jornalismo, assistia a poucos cursos e lia demais.

Então o meu aprendizado de jornalismo, talvez mais importante, [...] foram estes quase dois anos que passei lá, lendo jornais, revistas de jornalismo, como a Columbia Journalism Review e uma revista chamada The Quiver (A Pena). Assisti a muitas conferências de jornalistas importantes que iam ao campus (LINS DA SILVA, 2012, p. 126).

A terceira figura é consequência e efeito da anterior. O grupo formado por Eliane Brum, Alexandra Lucas Coelho, Carlos Eduardo Lins da Silva e Flávio Tavares ${ }^{13}$ se afastou, a partir de diferentes posições, do circuito de reprodução do saber jornalístico. Eliane ocupou, dentro da redação de Zero Hora, as bordas da formação, resistindo à disciplina; Alexandra, desde a experiência de enviada especial e correspondente internacional, desenvolveu

12 Alexandra Lucas Coelho, na época da entrevista, era correspondente internacional do jornal português Público. É autora dos livros Oriente Próximo, Caderno Afegão, Viva México, Tahrir - os dias da revolução e do romance E a noite roda.

13 Flávio Tavares é colunista de Zero Hora. Autor dos livros Memórias do esquecimento; O dia em que Getúlio matou Allende e $O$ Che Guevara que conheci e retratei. Foi correspondente internacional dos jornais Folha de S. Paulo, O Estado de S. Paulo e do jornal mexicano Excelsior. 
um modo jornalístico de se aproximar da realidade, que foi descrito também pelos outros jornalistas que foram forjados à distância do ambiente da redação.

O que desviou a trajetória profissional de Eliane daquela figura foi a cristalização de uma resistência singular e intensiva à segregação do outro, que, no jornalismo diário, repercute o comportamento social de controle através de táticas de exclusão do diferente, do anormal, daquele que não se enquadra na normalidade social. Alexandra parece ter-se voltado mais diretamente à resistência contra a pasteurização do outro em fonte, incluída no discurso jornalístico na função de mesmo, de um tipo sem contrastes, sem as diferentes nuances de todo ser humano.

Muitos exemplos podem ser desdobrados, na carreira de Eliane, desde a matéria sobre a inauguração da primeira loja do McDonald's em Porto Alegre, na Rua da Praia, publicada sem mudanças em Zero Hora. Em 1989, o jeito de olharem para ela no jornal começou a mudar.

Eu estava no plantão de domingo e saí com duas ou três pautas. E uma delas era a inauguração [...]. Então, uma pauta era isso: vai lá, vê quantos sanduíches foram vendidos, o que as pessoas dizem. Porque era um acontecimento para a cidade e, como todo mundo sabe, é um lugar histórico da cidade [...]. Eu nunca chego num lugar direto [...]. Eu fico sempre num canto, porque acho que esses cinco minutos que eu fico num canto olhando para a cena, antes de interferir na cena, são o que faz toda a diferença. [...]. Então, eu fiquei olhando para ver o que o McDonald's tinha alterado naquele mundo - não sei como é hoje, moro em São Paulo há 11 anos - naquele tempo [...] os tais velhinhos da Praça da Alfândega [...] sempre conversavam muito, era uma coisa agitada. Naquele dia eles estavam calados. [...] Então, em vez de entrar no McDonald's, sentei com eles e fiquei ali conversando e ouvindo-os sobre como eles viam tudo aquilo. [...] eles (ZH) gostaram da matéria e ela foi publicada pela primeira vez do jeito que escrevi (BRUM, 2012, p. 75).

Como repórter internacional, Alexandra rompeu com o senso comum de que "o mundo é pequeno". Ela já percebeu solidamente o mundo como algo infinito, porque pode atravessar os Estados Unidos, a África, o Afeganistão ou estar no centro do Brasil e as histórias que têm ouvido foram todas diferentes. A partir do momento em que se coloca frente a alguém, pensa: "Poderia ser eu." Essa percepção que dá inteireza, dignidade a qualquer pessoa que está diante de nós, tem a ver com a forma com que ela fala, com o som da voz, com os gestos e detalhes. Tudo que interessa é o que possa destacar as diferenças.

Aqui no Brasil me interessa muito ouvir o som, a forma como as pessoas falam. Porque me interessa que os ouvintes, que os leitores não leiam apenas: possam ver, possam ouvir. O texto é para ouvir também. [...] é para criar imagens, é para 
criar som, é para ter movimento. É um cinema. O texto tem muito do cinema [...]. Então, é um cinema com todos esses elementos, e o fascínio está em construir um cinema, mas apenas com palavras (COELHO, 2012, p. 163).

A última figura construída no processo de pesquisa reflete a autonomização e a conquista do estatuto autoral. O que se projeta nela é que o conhecimento de si e a autonomia profissional do jornalista levam à autoria que, no caso da produção jornalística, se desloca do coletivo e do horizonte disciplinar desenhado pelos controles discursivos próprios da prática. A diferença se dá em relação ao processo de produção, ao espaço e tempo jornalísticos e à elaboração das técnicas e dos procedimentos, que desnivelam a consciência prática da consciência discursiva. Neste patamar, os jornalistas tendem a buscar outras mídias.

Sem necessariamente deixar de fazer jornalismo, essa figura critica a prática fora da Redação, tida como o espaço próprio de circulação do saber jornalístico. No bojo dessa figura, em um novo espaço e em um novo tempo de produção, se insinuam quatro derivações. Em seu cotidiano, elas se autonomizaram das mídias jornalísticas para operarem no documentarismo, na literatura, na história e na memória. Eliane Brum experimentou os dois primeiros e Alexandra Lucas Coelho tem um desejo "que existe desde sempre", de viajar e escrever. O exercício do jornalismo foi uma travessia que permitiu fazer a ponte entre a escrita e o mundo, que permitiu viajar e ver o mundo.

No deslocamento do jornalismo para a literatura, Alexandra ganhou a posse de seus materiais. Um autor, diz ela, é inteiramente livre, o jornalista, não. No caso de Tahrir: um diário da revolução no Egito, em nenhum momento, ela pensou em ouvir um representante do governo, ou fontes policiais, porque o seu objetivo com o livro era transportar e transmitir a experiência física que teve entre os manifestantes que ocuparam a praça. Houve um momento em que ela saiu da praça e foi às pirâmides onde os separatistas criaram uma situação exterior em relação àquele espaço de protesto contra o governo. Esse esforço de deslocamento foi intuitivo, ela não seguia a determinação jornalística de buscar o outro lado da história; se houvesse uma pauta jornalística, provavelmente os dias que passou no Egito teriam sido planejados de outra forma.

Eliane Brum rompeu com a produtividade da fonte prescrita pelo jornalismo industrial ao eleger para as suas matérias os indivíduos à margem da sociedade. Desde a história que contou dos velhinhos da Praça da Alfândega, Eliane Brum forjou um modo de fazer jornalismo para dar voz a quem não tem voz. Com o passar do tempo, as redações foram ficando pequenas para isso; ela migrou para a internet, onde espaço não é problema. Nesse percurso, o ato de perguntar foi dando lugar à potência da escuta. Intuitivamente, na prática da reportagem, ela foi descobrindo que era assim que descobria alguma coisa nova, a partir da experiência do outro.

Eliane se considera agora uma escutadeira dos outros, no jornalismo, e de si mesmo, na literatura. Como escutadeira dos outros, ela acompanhou durante 115 dias, até a morte, 
o cotidiano de Ailce de Oliveira Souza, que tinha um câncer irreversível, sem perguntar que doença era aquela; na posição de repórter, preencheria uma lacuna da pauta se fizesse a pergunta: "Como é que lidas com o teu câncer". Silenciando a repórter, Eliane pôde compreender como a personagem da matéria, que foi publicada em O olho da rua, lidava com a própria doença. Neste papel, foi possível deslocar-se da relação objetiva e efêmera entre jornalista e fonte, sem, no entanto, ocupar o lugar de amiga; a escutadeira incorpora a repórter, a ponto de a personagem, ao longo da apuração, ter sido surpreendida com a ideia de que a repórter se dedicasse a outra coisa que não fosse ouvir a vida dela.

Ao longo da carreira, Eliane foi elaborando erros que traduziam um controle jornalístico sobre o seu trabalho, e outros espaços, do livro e do documentário, foram reservados às reflexões sobre o que ficava na margem das reportagens. Em O olho da rua, ela pretende compartilhar o que foi e o que não foi publicado com quem está começando na profissão, para que não cometa os mesmos erros, para que aprenda sem errar tanto como ela, que aprendeu errando, ou para que erre menos, porque o "mal que a gente faz é irreparável".

Os seus documentários tiveram relação direta com o jornalismo. O primeiro, Uma história Severina, trata da anencefalia, que, anteriormente, tinha sido tema de várias reportagens para a Época. Eliane queria ter mais tempo para acompanhar Severina, uma sertaneja que estava grávida de um feto anencéfalo e foi atrás de uma autorização judicial porque não suportava a ideia de ter uma gestação até o final de um bebê que iria morrer no parto ou pouco depois. Durante as férias da revista, fez o documentário em parceria com uma ONG, sem saber como se fazia um documentário. O road movie com a cantora Gretchen, segundo documentário, era para ter sido uma reportagem que não emplacou para a Época. A pauta era: o que uma mulher que passou 25 anos ganhando a vida com a bunda tinha a dizer sobre o país. A revista achou que a cantora não tinha nada a dizer, Eliane guardou a ideia; cinco anos depois, acompanhou Gretchen em uma turnê por circos mambembes do interior do Nordeste e a campanha dela para prefeita da Ilha de Itamaracá.

\section{Conclusões}

Nossa opção pela entrevista como modo de acesso à consciência discursiva dos repórteres vem possibilitando a construção de uma teoria da prática. Em trabalho anterior (2012), observamos e descrevemos o saber que circula ininterruptamente nas redações, os controles discursivos e, entre eles, o "comentário", que se atualiza no jornalismo sob a forma dos "livros de repórter".

No âmbito da prática, configurou-se um viés à margem da periodização histórica do jornalismo em três regiões que podem ser identificadas no jornalismo brasileiro em suas características dos anos 60 à contemporaneidade. A primeira região foi marcada pelo regime militar, pela atuação da censura, a separação nítida entre espaço editorial e espaço 
publicitário, pelo predomínio da grande empresa familiar no mercado jornalístico, pela Redação mecânica, organizada em editorias, por um conjunto de funções com fronteiras definidas para dar conta de textos e das imagens, pela forte influência de formas literárias de jornalismo, entre outros fatores. Na segunda, prevalecem a retomada democrática e o avanço da informatização nas redações. Nesta zona, o progresso da informática provocou novas concepções espaciais que afetaram o trabalho e os seus produtos. Politicamente, o jogo de forças se modificou e isso implicaria novas relações entre jornalismo e instituições sociais. Em termos gráficos e editoriais, há profundas afetações. A terceira região abriga a ruptura definitiva com o espaço geográfico, físico e com o lugar da Redação. Com os processos em base digital, o jornalismo passa a oferecer notícias onipresentes, acesso global à informação, cobertura instantânea, interatividade, conteúdos multimídia e extrema personalização do conteúdo (PAVLIK, 2005, p. 13).

A tensão entre os controles discursivos e a resistência dos repórteres perpassou todo o período estudado, primeiro com táticas de "contrabando" para driblar a censura política, depois a resistência foi voltada à censura econômica da empresa. Nas entrevistas, os profissionais remeteram a outros espaços e prazos de produção que conquistaram ao longo de suas carreiras, em diferentes derivações dos jornalísticos em que, ao se descolarem da disciplina, esboçaram potenciais figuras de autor (MAROCCO, 2012).

A tipologia que damos a conhecer no presente texto evidencia que as operações de controle discursivo blindam a disciplina das resistências que lhe correspondem; em suas formas, no entanto, as resistências vêm à tona e é nelas, segundo a experiência de nossos entrevistados, que germina a autonomização dos repórteres e o seu deslocamento da autoria coletiva para uma autoria individual. Neste ponto, as mídias se conjugam a um outro espaço igualmente jornalístico, o "livro de repórter", em que se materializa o "comentário" sobre a prática jornalística que não tem lugar no jornalismo senão ali, onde os repórteres encontram tempo para proceder a uma análise epistemológica reflexiva.

Beatriz Alcaraz Marocco é professora do PPGCC da Unisinos.

beatrizmarocco@uol.com.br

\section{Referências}

DENT, Chris. Journalists are the confessors of the public, says one Foucaultian. Journalism, 9(2):200219.

FOUCAULT, M. A ordem do discurso [1973]. São Paulo: Edições Loyola, 1996. Microfísica do poder [1979], 11 a ed. Rio de Janeiro: Graal, 1993. 
Mesa redonda em 20 de maio de 1978 [1980]. In: MOTTA, Manoel Barros da. Foucault. Estratégia, poder-saber. Rio de Janeiro: Forense Universitária: 2006.

GIDDENS, Anthony. A constituição da sociedade. São Paulo: Martins Fontes, 2009, $3^{\text {a }}$ ed. MAROCCO, Beatriz. O jornalista e a prática. São Leopoldo: Editora Unisinos, 2012.

Entrevista na prática jornalística e na pesquisa. Porto Alegre: Libretos, 2012a.

MEDINA, Cremilda. Entrevista. O diálogo possível. São Paulo: Ática, 1990.

Ciência e jornalismo. Da herança positivista ao diálogo dos afetos. São Paulo: Summus, 2008.

MORIN, Edgar. De la entrevista. In: MORIN, Edgar. Sociología. Madrid: Tecnos, $20002^{\text {aed. }}$

Artigo recebido em novembro de 2014 e aprovado em janeiro de 2015. 